\title{
Angiotensin-converting Enzyme Inhibitors-induced Angioedema
}

\author{
Anca Chiriac ${ }^{1,2,3}$, Piotr Brzezinski ${ }^{4,5,6,7}$, Mircea Betiu ${ }^{8}$, Liliana Foia ${ }^{9}$ \\ ${ }^{1}$ Nicolina Medical Center, Department of Dermatology, Iași, Romania \\ ${ }^{2}$ Apollonia University, Iași, Romania \\ 3 "P. Poni" Research Institute, Romanian Academy, Iasi \\ ${ }^{4}$ Department of Dermatology, 6th Military Support Unit, Ustka, Poland \\ ${ }^{5}$ Department of Dermatology, Provincial Specialist Hospital in Slupsk, Ustka, Poland \\ ${ }^{6}$ Institute of Biology and Environmental Protection, Pomeranian Academy, Slupsk, Poland \\ ${ }^{7}$ Faculty of Mathematics and Natural Sciences, Institute of Biology and Environmental Protection, Pomeranian Academy, Slupsk, Poland \\ ${ }^{8}$ Department of Dermatovenereology, "Nicolae Testemitanu" State University of Medicine and Pharmacy, Chișinău, Republic of Moldova \\ 9 "Grigore T Popa" University of Medicine and Pharmacy, Iași, Romania
}

\section{ABSTRACT}

Angiotensin-converting enzyme inhibitors (ACEI) are widely used drugs nowadays in treating patients diagnosed with cardiovascular disorders. We present two consecutive cases of acquired angioedema caused by the administration of enalapril and lisinopril in patients with indication for ACE-inhibitors therapy. Rigorous follow-up of side effects of ACEI is required, due to these possible life-threatening adverse reactions.

Keywords: angiotensin-converting enzyme inhibitors, angioedema, adverse reactions

\section{ARTICLE HISTORY}

Received: February 12, 2018

Accepted: March 12, 2018

\section{CORRESPONDENCE}

\section{Anca Chiriac}

Str. Hatman Șendrea nr. 2

700613 Iași, Romania

Tel: +40 332808703

E-mail: ancachiriac@yahoo.com

\section{INTRODUCTION}

Angiotensin converting enzyme inhibitors (ACEI) represent a frequently used medication in daily practice, although little is known about the risk of side effects and mainly about acquired angioedema, a life-threatening complication. Cutaneous adverse reactions labeled on the medication cover a large variety of skin lesions such as urticaria, lichenoid dermatosis, pemphigus, photosensitivity reactions, and angioedema. ${ }^{1}$
The first description of angioedema dates from 1876 and belongs to Milton, the terminology of angioneurotic angioedema being used later by Quincke, in $1822 .{ }^{2}$ In current daily practice the expression angioedema fully describes the clinical entity that consists of facial edema, including the eyelids, lips, and upper respiratory tract.

Drug-induced angioedema has been reported in association with the administration of various drugs such as nonsteroidal anti-inflammatory drugs, antibiotics, 
statins, proton pump inhibitors, estrogens, radiocontrast agents, ACEI, beta blockers, calcium channel blockers, and this list can be exhaustive, by recent reports. ${ }^{3}$

We present two consecutive cases of acquired angioedema caused by the administration of enalapril and lisinopril in patients with indication for ACEI therapy.

The patients consented to the publication of their data and approval from the institution where they had been admitted was also obtained.

\section{CASE SERIES}

\section{CASE 1}

A 74-year-old male Caucasian patient was seen in the Emergency Unit for diffuse facial and eyelid angioedema (Figure 1). The patient had been under treatment with enalapril for arterial hypertension. Monotherapy with ACEI was started 2 weeks previously. He was treated with parenteral and oral corticosteroids associated with systemic antihistamines, the ACEI were discontinued, and the patient presented a full recovery.

\section{CASE 2}

A 56-year-old female patient was referred to the Dermatology Clinic for severe lower lip edema (Figure 2). The onset of symptoms had been observed 6 hours prior to hospital admission, with progressive worsening; however, after a complete clinical examination, no other systemic or cutaneous findings were reported. The patient had been diagnosed with arterial hypertension nine months

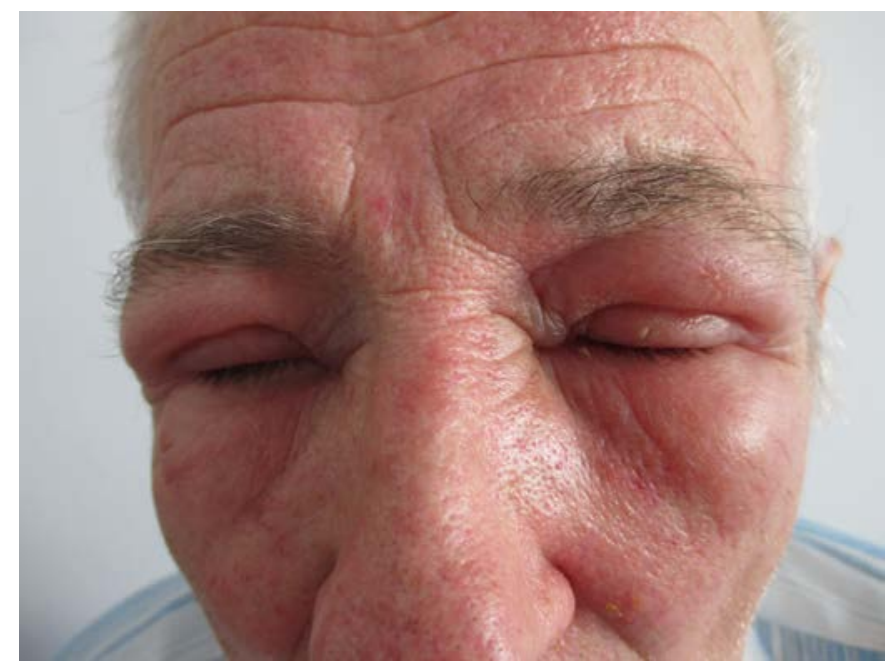

FIGURE 1. Diffuse facial and eyelid angioedema during treatment with enalapril for arterial hypertension in a 74 -year-old patient prior the current presentation, for which she had been prescribed lisinopril in monotherapy. The patient denied any other drug intake, and she did not have any history of allergy. The suspected clinical diagnosis was lisinoprilinduced angioedema, which led to the discontinuation of the medication and the administration of antihistamines and systemic steroids.

\section{DISCUSSIONS}

The diagnosis of angioedema is mainly clinical and is suggested by the occurrence of non-pitting edema, regularly involving the cephalic extremity, more specifically the tongue and lips, as well as the face and throat. It may be a life-threatening condition as it can cause airway swelling with acute respiratory distress, in which case the patient requires immediate hospital admission and emergency treatment. Angioedema is classified as allergic and nonallergic according to its etiology. ${ }^{4}$

In order to provide a proper patient management, it is of outmost importance to conduct a differential diagnosis between histamine- and bradykinin-mediated angioedema. $^{5}$

Angioedema induced by histamines released from mast cells is associated with urticaria and pruritus, and its triggers include viral infections, drugs, food, or physical causes (cold, heat, vibration, pressure, water, sun exposure). The response to antihistamines, epinephrine and/or steroids is the main feature of this manifestation; severe cases may need the administration of omalizum$\mathrm{ab}$ or cyclosporine, according to the latest guidelines. Abdominal pain and rapid onset are also useful criteria

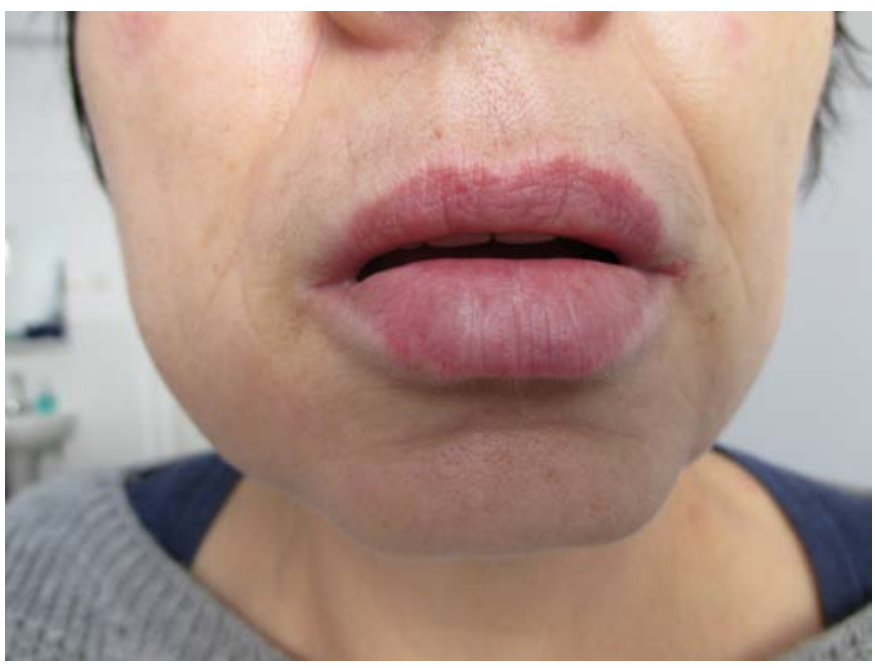

FIGURE 2. Severe lower lip edema in a 54-year-old patient treated with lisinopril 
for differentiating it from bradykinin-mediated angioedema.

Bradykinin-mediated angioedema includes hereditary angioedema and acquired angioedema; urticaria and pruritus are absent, the onset is not abrupt but slow and progressive, over hours, culminating in severe clinical manifestations and abdominal pain; another clue is the lack of response to antihistamines and steroids. ${ }^{6}$

Hereditary angioedema is an autosomal dominant disease caused by the lack of or a dysfunctional C1-inhibitor protein and is bradykinin-mediated. The other form is acquired bradykinin-mediated angioedema, which includes the drug-induced type. ${ }^{?}$

Angioedema induced by ACEI is bradykinin-mediated, being based on the inhibition of ACE, which further inhibits the conversion of angiotensin and diminishes the catabolism of bradykinin. ${ }^{8}$

Angioedema caused by ACEI has been reported in 0.1$0.7 \%$ of patients treated with different types of ACEI. ${ }^{9} \mathrm{Al}-$ most one third of the patients with ACEI-induced angioedema had severe or fatal forms, resistant to treatment. ${ }^{10}$ The disorder has been reported at the beginning of treatment, although this side effect can occur at any time during drug administration. ${ }^{11}$ The currently prescribed ACEIs are enalapril, lisinopril, captopril, ramipril, imidapril, benazepril, trandolapril, and perindopril, but not all patients are prone to develop this severe adverse reaction in reaction to ACEIs. Several studies have been conducted to identify risk factors related to ACEI-induced angioedema. The main reported risk factors include black race, female gender, smoking, personal history of allergies or atopy, elderly, obesity (high body mass index), previous upper respiratory disorders, sleep apnea, and immunosuppression. ${ }^{12-14}$

Treatment of patients diagnosed with ACEI-induced angioedema starts with the recognition of angioedema and of the fact that ACEI could be possible etiologic factors of recurrent facial and upper respiratory edema. ${ }^{15}$ The most important recommendation in these cases is to avoid ACEI and revise the medication.

In emergency units angioedema should be treated according to guidelines. ${ }^{16}$ The treatment of ACEI-induced angioedema includes icatibant, a bradykinin inhibitor, currently used in patients with hereditary angioedema, or ecallantide, a plasma-derived C1 esterase inhibitor. ${ }^{17-20}$

The presented cases are two examples of ACEI-induced angioedema, both patients having prescribed angiotensin converting enzyme inhibitors for arterial hypertension. However, the first patient presented the adverse reaction within the first two weeks from initiation of treatment, while the second had a late-onset adverse angioedema. Current reports state that in approximately half of cases, angioedema occurs in the first 90 days from initiation of ACEI treatment, while others present the adverse reaction even as late as over 12 months. ${ }^{9}$ The patients depicted in the present manuscript presented favorable outcomes after discontinuation of ACEI and administration of antihistamines and steroidal anti-inflammatory medication. Despite this, both patients needed continuous monitoring and observation for progressive airway obstruction, which would have required intubation and mechanical ventilation.

\section{CONCLUSION}

Angioedema associated with angiotensin converting enzyme inhibitors is a clinical diagnosis and should be recognized by treating physicians in hospitals and emergency units. The main therapeutic measure is represented by the cessation of ACEI medication. Such patients require careful observation for airways compromise and acute respiratory failure, in which case mechanical ventilation is used.

\section{CONFLICT OF INTEREST}

Nothing to declare.

\section{REFERENCES}

1. Korzeniowska K, Cielewiczi A, Pawlaczyk M, Motowidlo K, Andrys-Wawrzyniak I, Jablecka A. Angioedema after angiotensin-converting enzyme inhibitors. Acta Pol Pharm. 2017;74:983-986.

2. Cicardi M, Agostoni A. Hereditary angioedema. N Engl J Med. 1996;334:1666-1667. doi:10.1056/NEJM199606203342510.

3. Sánchez-Borges M, González-Aveledo L. AngiotensinConverting Enzyme Inhibitors and Angioedema. Allergy Asthma Immunol Res. 2010;2:195-198. doi: 10.4168/ aair.2010.2.3.195.

4. Lewis LM. Angioedema: etiology, pathophysiology, current and emerging therapies. J Emerg Med. 2013;45:789-796. doi: 10.1016/j.jemermed.2013.03.045.

5. Bas M, Adams V, Suvorava T, Niehues T, Hoffmann TK, Kojda G. Nonallergic angioedema: role of bradykinin. Allergy 2007;62:842-56. doi: 10.1111/j.1398-9995.2007.01427.x.

6. Banerji A. Current treatment of hereditary angioedema: An update on clinical studies. Allergy Asthma Proc. 2010;31:398406. doi: 10.2500/aap.2010.31.3387.

7. Baram M, Kommuri A, Sellers SA, Cohn JR. ACE inhibitorinduced angioedema. J Allergy Clin Immunol Pract. 2013;1:442445. doi: 10.1016/j.jaip.2013.07.005.

8. Mlynarek A, Hagr A, Kost K. Angiotensin-converting enzyme inhibitor-induced unilateral tongue angioedema. Otolaryngol Head Neck Surg. 2003;129:593-595. doi: 10.1016/S019459980300724-1. 
9. Miller DR, Oliveria SA, Berlowitz DR, Fincke BG, Stang $\mathrm{P}$, Lillienfeld DE. Angioedema incidence in US veterans initiating angiotensin-converting enzyme inhibitors. Hypertension. 2008;51:1624-1630. doi: 10.1161/ HYPERTENSIONAHA.108.110270.

10. Cupido C, Rayner B. Life-threatening angio-oedema and death associated with the ACE inhibitor enalapril. S Afr Med J. 2007;97:244-245.

11. Chin HL, Buchan DA. Severe angioedema after long-term use of an angiotensin-converting enzyme inhibitor. Ann Intern Med. 1990;112:312-313.

12. Kostis JB, Kim HJ, Rusnak J, et al. Incidence and characteristics of angioedema associated with enalapril. Arch Intern Med. 2005;165:1637-1642. doi: 10.1001/archinte.165.14.1637.

13. Morimoto T, Gandhi TK, Fiskio JM, et al. An evaluation of risk factors for adverse drug events associated with angiotensinconverting enzyme inhibitors. J Eval Clin Pract. 2004;10:499509. doi: 10.1111/j.1365-2753.2003.00484.x.

14. Abbosh J, Anderson JA, Levine AB, Kupin WL. Angiotensin converting enzyme inhibitor-induced angioedema more prevalent in transplant patients. Ann Allergy Asthma Immunol. 1999;82:473-476. doi: 10.1016/S1081-1206(10)62723-8.
15. Weber MA, Messerli FH. Angiotensin-converting enzyme inhibitors and angioedema: estimating the risk. Hypertension. 2008;51:1465-1467. doi: 10.1161/ HYPERTENSIONAHA.108.111393.

16. Riedl M. Hereditary angioedema therapies in the United States: movement toward an international treatment consensus. Clin Ther. 2012;34:623-630. doi: 10.1016/j.clinthera.2012.02.003.

17. Farkas H, Martinez-Saguer I, Bork K, et al. International consensus on the diagnosis and management of pediatric patients with hereditary angioedema with C1 inhibitor deficiency. Allergy. 2017;72:300-313. doi: 10.1111/all.13001.

18. Betschel S, Badiou J, Binkley K, et al. Canadian hereditary angioedema guideline. Allergy Asthma Clin Immunol. 2014;10:50. doi: 10.1186/1710-1492-10-50.

19. Bork K. An evidence based therapeutic approach to hereditary and acquired angioedema. Curr Opin Allergy Clin Immunol. 2014;14:354-362. doi: 10.1097/ACI.0000000000000082.

20. Bernstein JA, Moellman JJ. Progress in the emergency management of hereditary angioedema: focus on new treatment options in the United States. Postgrad Med. 2012;124:91-100. doi: 10.3810/pgm.2012.05.2552. 